\title{
Hostile Interactions of Punjab Urial (Ovis vignei punjabiensis) towards Indian Gazelle (Gazella bennettii) during Feeding Sessions in Captive Breeding Settings
}

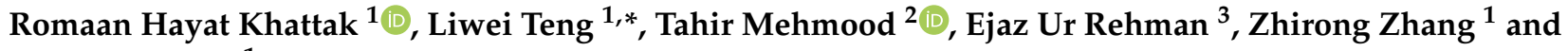 \\ Zhensheng Liu ${ }^{1, *}$ \\ 1 College of Wildlife and Protected Areas, Northeast Forestry University, Harbin 150040, China; \\ romaanhayatkhattak@nefu.edu.cn (R.H.K.); zhang_zr@126.com (Z.Z.) \\ 2 School of Natural Sciences (SNS), National University of Science and Technology (NUST), \\ Islamabad 44000, Pakistan; tahime@gmail.com \\ 3 Snow Leopard Trust, Islamabad 44000, Pakistan; ejazrehman53@gmail.com \\ * Correspondence: tenglw1975@163.com (L.T.); zhenshengliu@163.com (Z.L.)
}

check for updates

Citation: Khattak, R.H.; Teng, L.; Mehmood, T.; Rehman, E.U.; Zhang, Z.; Liu, Z. Hostile Interactions of Punjab Urial (Ovis vignei punjabiensis) towards Indian Gazelle (Gazella bennettii) during Feeding Sessions in Captive Breeding Settings. Animals 2021, 11, 1274. https://doi.org/ 10.3390/ani11051274

Academic Editor: Fabienne Delfour

Received: 14 March 2021

Accepted: 27 April 2021

Published: 28 April 2021

Publisher's Note: MDPI stays neutral with regard to jurisdictional claims in published maps and institutional affiliations.

Copyright: (c) 2021 by the authors. Licensee MDPI, Basel, Switzerland. This article is an open access article distributed under the terms and conditions of the Creative Commons Attribution (CC BY) license (https:// creativecommons.org/licenses/by/ $4.0 /)$.
Simple Summary: Multiple factors, both natural and anthropogenic, are driving most of the wild species to the verge of extinction across the globe. In order to conserve these threatened species, various conservation interventions and strategies are adopted, among which is re-introduction of captive stocks of species into the wild habitats where they vanished from. Captive breeding is one of the promising tools for endangered species preservation. Providing social enrichment to the captive stocks is an important step in the management, in particular for stocks, which are aimed for re-introduction. The subject species of this study, i.e., Punjab urial (Ovis vignei punjabiensis) and Indian gazelle (Gazella bennettii) are being reared in captivity with the aim of re-introduction. As there is scarcity of information regarding the behavioral aspects of captive species, especially ungulates, this study aimed at understanding the dynamics of their interactions. The current study reported that Punjab urial, being the dominant species, exerts itself on the submissive and subordinate species, the Indian gazelle. This negative interference can possibly lead to negative ramifications in the form of stress and injuries in the short term, while negative effects on population growth in the long term. Thus, this study recommends separate rearing of these species to eliminate the hazardous competition between them.

Abstract: Natural wildlife habitats are regularly subjected to anthropogenic pressures for different purposes, which are heading the biodiversity towards drastic decline. Several endangered wild species are raised in captivity with the aim of re-introduction. In some instances, mixed herds' rearing approach in captivity is adopted for providing social enrichment to captive stocks; however, the impacts of species on each other are least documented. We tested our prediction that keeping mixed herds of captive wild sheep and antelopes provides adequate social enrichment to the captive stocks: if interspecific interactions are balanced. In the current study, we studied the interspecific competition between mixed herds of captive Punjab urial (Ovis vignei punjabiensis) and Indian gazelle (Gazella bennettii) at Manglot Wildlife Park, Nowshera District, Khyber Pakhtunkhwa Province, Pakistan. We documented the negative effects of behavioural interference by Punjab urial on the feeding behaviour of Indian gazelle. The outcome of the current study revealed that Punjab urial are highly intolerant towards Indian gazelle, with high interference during feeding. Out of the total aggressive events, $77 \%(N=1259)$ of events ended up with win/loss, in which Punjab urial dominated the Indian gazelle 3.5 times. Moreover, lopsided dominance by Punjab urial resulted in increased intraspecific competition among Indian gazelle $(p<0.001)$. Current study divulged Indian gazelle to be the subordinate species, with less intake of food. Instead of providing social enrichment by heterospecifics, the Punjab urial is negatively affecting the Indian gazelle, therefore, the results of our study discourage the practice of admix captive breeding for wild sheep and antelopes. 
Keywords: captive ungulates; behavioural intolerance; social enrichment; mixed herds; Ovis vignei punjabiensis; Gazella bennettii; interspecific interactions; Pakistan

\section{Introduction}

Investigating the interspecific competitions among individuals is of utmost importance both in the wild and in captivity. These interactions for resources can affect the species' growth rates, survival, and fitness [1]. Competition between species may be "exploitative competition" comprised of indirect negative interactions, resulting from common resources [2]. On the other hand "interspecific interference competition" is where one species limits and reduces other species' ability to utilise the shared resources by its presence or agonistic interactions, and are ubiquitous [3]. Such interactions have been documented in a wide range of taxa, ranging from small mammals (rodents and bats) up to big mammals including carnivores and large herbivores [4-10]. Such agonistic interactions can possibly result in severe injuries and ultimately deaths [11,12], primarily when the competing species are restricted to confined areas. In such cases, the interspecific competitions lead to reduced intake of energy resulting in poor health, poor reproduction, and poor population growth [13]. Interspecific interactions are frequently lopsided, where the smaller species are more prone to lose the agonistic contests for resources with larger species, which are usually characterised by the physical attributes, i.e., strength and weapons (tusks, antlers and horns) [14]. In such cases, the smaller submissive species are expected to undergo behavioural changes to avoid dominant species [15]. However, such avoidance behaviours stop the smaller species from utilising the valuable food resources [15], and can have very unpleasant effects in captive environments, where the food is supplied in due quantity and time.

Overall, the interspecific competitions are believed to play a vital role in shaping the wild animal communities including ungulates $[16,17]$. In the wild natural environments, different ungulate species have been sympatric through evolution, which allows them to co-exist with one another [18]. In the natural wild habitats, the exploitative competition among ungulates is lessened, and sympatry is maintained by mechanisms like resource partitioning, consuming different forage species, or foraging other parts of the same species [19]. However, in captivity, resource partitioning is often influenced by behaviour, and thus, sympatric ungulates develop strong unpleasant aggressions to limit the food intake by other counterparts [19]. Interspecific aggression is much more common in carnivores [20], and least documented in herbivores [21,22].

The competitive success in animals is best defined as to have increased access to quality food [23,24], and controlling optimal shelter [25], which is mostly very true for wild animals in captivity with limited resources. Competitive failures may reduce the fitness of the loser animal, as it may be underprivileged by reduced access to food, dispossession of optimal shelter or receiving direct injuries from the powerful individual during the fight $[26,27]$. Thus, the losers and deprived individuals are much more prone to stress that can efficiently reduce the physiological processes, reproduction and survival probabilities and population growth rates $[28,29]$.

During the last decades, populations of many wild species have been drastically declined and are facing increased extinction risks, and many of them are reared in captivity with the aim of re-introduction. This is also true for many wild animal species in Pakistan. Punjab urial (Ovis vignei punjabiensis) is a sub-species of Urial (Ovis vignei) and is exclusively endemic to Pakistan, while Indian gazelle (Gazella bennettii), a representative of antelopes; both are categorised endangered through local assessment, and are raised in captivity with the aim of re-introduction into the wild in Khyber Pakhtunkhwa (KP) Province of Pakistan [30-32]. Even though the institutions keeping wild animals in captivity try their best to provide adequate food, it is challenging to balance overfeeding and reduce harmful effects of competitions [29]. Therefore, competition in captivity is much higher than in 
the wild, with higher densities and lower food availability [33]. Extensive competitions arise in captivity when loser animals fail to secure sufficient food and potentially suffer from unpredictable supply [34-36], while the dominant animals overfeed. With the increase of competition for food, aggression levels rise and subsequently, the stress [36]. For promising captive breeding programmes, the goal is to provide enough food for each animal and maintain an acceptable level of competition [1]. To reduce the competition among conspecifics, an alternative option is to keep animals solitary, however, lack of social interactions will have adverse effects on stocks which are supposed to be used in re-introduction programmes [37,38].

In captive breeding practices, along with the provisions of appropriate environments that focus on physical aspects (enclosure size and design) and food enrichment (variety, processing and presentations) [39], social enrichment is also potentially significant [40]. Usually, the social enrichment is provided by the conspecifics, however, the other species (heterospecifics) may also have the potential for boosting animal welfare [40]. Keeping wild animals in mixed species groups is one such way to provide animals with complex physical and social environments [39], and an acceptable level of competitions where there is a balance between two species; these are signs of optimal animal welfare [41]. However, extreme interspecific competitions will result in many unpleasant scenarios like aggressions and stress [41], and may have adverse effects on the subordinate species and thus reflect poor management. We assumed keeping mixed herds of captive wild sheep and antelopes provides adequate social enrichment to the captive stocks: if interspecific interactions are balanced. The current study was thus designed to investigate (1) the interspecific interactions during feeding between mixed herds of captive breeding Punjab urial and Indian gazelle, and (2) to find the dominance and compatibility between these two species.

\section{Materials and Methods}

\subsection{Study Area}

The current study was conducted at the captive breeding facility located at Manglot Wildlife Park (MWP) $\left(33^{\circ} 45^{\prime} 19^{\prime \prime} \mathrm{N}, 72^{\circ} 0^{\prime} 15^{\prime \prime} \mathrm{E}\right)$, Nowshera district, KP province Pakistan. The study area has a predominant scrub forest with semi-arid climate. The average annual temperature recorded is $24.4^{\circ} \mathrm{C}$ with an average rainfall of $532 \mathrm{~mm}$. Mixed herds of Punjab urial and Indian gazelle are raised in an enclosure encompassing an area of $15,793 \mathrm{~m}^{2}$. In addition to the two species mentioned above, three males of Mouflon sheep (Ovis orientalis) were also present in the same enclosure. However, before conducting this study, the three male Mouflon sheep were shifted by the wildlife and park authorities into a zoo located in the Peshawar district of KP province. This study was carried out from 26 November-26 December 2020.

\subsection{Study Animals}

During the study period, a total of 15 individuals were present in the enclosure, including 8 Punjab urial and 7 Indian gazelle. It was not allowed to restrain or capture the study animals for tagging. Therefore, we performed a preliminary survey to identify every individual based on the demographic and physical features (Table 1). Codes were allotted to each particular individual. 
Table 1. Study animal's description with respect to demography and allotted id's.

\begin{tabular}{|c|c|c|c|}
\hline s.no & Animal ID & Demography & Description \\
\hline 1 & UM1 & Adult urial male & $\begin{array}{l}\text { Horns curled downward, dark reddish-brown coat color, conspicuous vertical } \\
\text { white saddle mark, long extended ruff comprised of mixed white and black hairs }\end{array}$ \\
\hline 2 & UM2 & Adult urial male & $\begin{array}{l}\text { Horns curled downwards, reddish coat color, saddle mark absent, extensive ruff } \\
\text { with mostly white hairs in the throat and black hairs on the chest area }\end{array}$ \\
\hline 3 & UM3 & Sub-adult urial male & $\begin{array}{l}\text { Horns comparatively shorter and curled downward, saddle mark absent, ruff was } \\
\text { like a flat black strip extended through the chest without extensively long hairs }\end{array}$ \\
\hline 4 & UM4 & Yearling urial male & $\begin{array}{l}\text { Sickle-shaped horns curled backward, somewhat greyish coat color, ruff } \\
\text { not conspicuous. }\end{array}$ \\
\hline 5 & UF1 & Adult urial female & Grey coat color, one horn broken, with young UY1F1 \\
\hline 6 & UF2 & Adult urial female & Grey coat color, both horns present, with young UY2F2 \\
\hline 7 & UY1F1 & Urial lamb & Offspring of UF1, comparatively healthy and bigger than UY2F2 \\
\hline 8 & UY2F2 & Urial lamb & Offspring of UF2, comparatively weaker and smaller than UY1F1 \\
\hline \multicolumn{4}{|c|}{ Indian gazelle } \\
\hline 1 & GM1 & Adult gazelle male & Dark greyish sandy color, longhorns \\
\hline 2 & GM2 & Adult gazelle male & Greyish sandy colour, horns were comparatively shorter than GM1 \\
\hline 3 & GF1 & Adult gazelle female & Greyish sandy colour, with young (GY1F1) \\
\hline 4 & GF2 & Adult gazelle female & Greyish sandy colour, with young (GY2F2) \\
\hline 5 & GF3 & Adult gazelle female & Greyish sandy colour, without any young \\
\hline 6 & GY1F1 & Gazelle fawn & Offspring of GF1, comparatively bigger than GY2F2 \\
\hline 7 & GY2F2 & Gazelle fawn & Offspring of GF2, comparatively smaller than GY1F1 \\
\hline
\end{tabular}

\subsection{Control Group}

We recognised that this study lacks a control group for direct comparison, as there were no opportunities to separate the animals into single-species enclosures for the purposes of this research. An alternative would be to consider a wild population as a control group because urial and gazelle rarely occupy the same spaces in the wild. However, we could not use the wild case as a control group because although urial and gazelle exist independently in the wild, i.e., equivalent to single-species enclosures and can be considered a suitable control group; yet, they occur at such low densities that it was not realistic to locate and assess wild individuals, and we also expect captive and wild individuals to have some behavioural dissimilarities.

\subsection{Behavioural Observations}

During this study, all the data were collected only during feeding hours. Study animals were fed twice a day (morning and late afternoon), and all the threat displays were recorded on specified sheets. While recording the events, it was assumed that when a receiver left the feed due to the actor's threat, it was considered a "displacement event". It did not matter if the receiver left the feed for a very short time. If a displacement event occurs, that was considered a "win" for actor and a "loss" for the receiver. On the other hand, if the receiver did not leave the feed in response to the actor's threat, it was considered an "event with no outcome". A single vantage point outside the enclosure was selected for observations. The vantage point was converted into a temporary camouflaged hide to minimise observers' effect on animals' behaviour. Moreover, data was recorded until it was assured that all animals left the feed and were no more interested in eating. Start and end time of each particular observation was recorded.

On the first day of observation, the feed was put down in two points as per regular practice by the keepers. However, due to animals' clumping, it was difficult to identify the actor and receiver animal quickly and to adequately record the events. Therefore, in the following days, the number of feed points were increased up to 5, at a distance of approximately $15 \mathrm{~m}$ apart.

\subsection{Statistical Analysis}

All the data were analysed by using matrices [42] and descriptive statistics. To investigate the effects of Punjab urial on Indian gazelle, we pooled out the interspecies interactions 
events data. To find out the difference between the interspecific and intraspecific aggressions and sexes, we performed the non-parametric McNemar's Chi-square test, by using function monemar.test in R-package version 3.5.1. Significance level was set at $p<0.05$.

\section{Results}

\subsection{Overall Interactions}

With an effort of $23.16 \mathrm{~h}$, a total of seven threat behaviours (Table 2) were recorded, yielding a total of 1635 agonistic interaction events among all the individuals. Out of the total events, $77 \%(N=1259)$ of events ended up with win/loss, and $23 \%(N=376)$ of events were ended with no outcome (Table 3). Out of the total events ended up with wins/loses, Punjab urial won $67.8 \%(N=854)$, and Indian gazelle won $32.2 \%(N=405)$ events. Among Punjab urial, UM3 scored the highest number of wins with $36.12 \%(N=309)$, followed by UM1, UM2 and UF2, with a win percentage of $24.35 \%(N=208), 12.29 \%(N=105)$, and $11.47 \%(N=98)$, respectively.

Table 2. Recorded threat behaviours, displayed by Punjab urial and Indian gazelle during observations.

\begin{tabular}{cc}
\hline Behaviour & Description \\
\hline $\begin{array}{c}\text { Approach } \\
\text { Butt }\end{array}$ & $\begin{array}{c}\text { The actor walks straight towards the receiver. } \\
\text { Tush }\end{array}$ \\
The actor pushes the receiver, either frontal head-to-head push or receiver \\
attains a push from actor at any part of the body. \\
Kick & The actor turns its head towards the receiver and gently growls without butting. \\
Mount & $\begin{array}{r}\text { The actor kicks the receiver with hind leg. } \\
\text { The actor mounts on the receiver. }\end{array}$ \\
\hline
\end{tabular}

Table 3. Number of aggressive interactions (wins/losses) among Urial-Gazelle, Urial-Urial and Gazelle-Gazelle $\left(\chi^{2}=846.4\right.$, $\mathrm{df}=165, p<0.001)$.

\begin{tabular}{|c|c|c|c|c|c|c|c|c|c|c|c|c|c|c|c|c|}
\hline & Loser & & & & & & & & & & & & & & & \\
\hline Winner & GF1 & GF2 & GF3 & GM1 & GM2 & GY1F1 & GY2F2 & UF1 & UF2 & UM1 & UM2 & UM3 & UM4 & UY1F1 & UY2F2 & $\begin{array}{l}\text { Total } \\
\text { Wins }\end{array}$ \\
\hline GF1 & 0 & 0 & 22 & 3 & 3 & 0 & 6 & 0 & 1 & 0 & 0 & 0 & 1 & 2 & 4 & 42 \\
\hline GF2 & 1 & 0 & 11 & 5 & 0 & 4 & 1 & 3 & 0 & 0 & 0 & 0 & 0 & 1 & 0 & 26 \\
\hline GF3 & 6 & 6 & 0 & 1 & 2 & 19 & 16 & 2 & 1 & 0 & 1 & 0 & 2 & 4 & 5 & 65 \\
\hline GM1 & 7 & 12 & 34 & 0 & 25 & 15 & 26 & 9 & 8 & 0 & 0 & 1 & 10 & 2 & 4 & 153 \\
\hline GM2 & 13 & 4 & 24 & 5 & 0 & 24 & 8 & 10 & 6 & 0 & 0 & 0 & 15 & 4 & 6 & 119 \\
\hline UF1 & 5 & 10 & 21 & 3 & 3 & 0 & 11 & 0 & 4 & 0 & 0 & 0 & 11 & 0 & 9 & 77 \\
\hline UF2 & 20 & 6 & 23 & 2 & 2 & 8 & 1 & 11 & 0 & 0 & 1 & 0 & 12 & 12 & 0 & 98 \\
\hline UM1 & 6 & 4 & 13 & 17 & 24 & 2 & 3 & 8 & 17 & 0 & 9 & 37 & 37 & 13 & 18 & 208 \\
\hline UM2 & 2 & 1 & 7 & 14 & 2 & 1 & 3 & 13 & 6 & 7 & 0 & 11 & 24 & 9 & 4 & 105 \\
\hline UM3 & 17 & 14 & 24 & 35 & 13 & 5 & 3 & 35 & 25 & 27 & 19 & 0 & 56 & 19 & 17 & 309 \\
\hline UM4 & 5 & 1 & 16 & 4 & 4 & 4 & 3 & 4 & 0 & 0 & 0 & 0 & 0 & 9 & 7 & 57 \\
\hline $\begin{array}{c}\text { Total } \\
\text { Losses }\end{array}$ & 82 & 58 & 195 & 90 & 78 & 82 & 81 & 95 & 68 & 34 & 30 & 49 & 168 & 75 & 74 & 1259 \\
\hline
\end{tabular}

Among Indian gazelle, GM1 scored the highest win percentage of $37.77 \%(N=153)$ followed by GM2 and GF3, with $29.38 \%(N=119)$ and $16.04 \%(N=65)$, respectively.

\subsection{Urial-Gazelle Interactions}

Out of total wins $(N=854)$ by Punjab urial, $42.38 \%(N=362)$ were attained against Indian gazelle $(\mathrm{U}-\mathrm{G})$. Out of total wins by Indian gazelle, reversal wins $(\mathrm{G}-\mathrm{U})$ against Punjab urial were $25.18 \%(N=102)$ (Figure 1$)$. Results obtained from McNemar's Chi-square test revealed that there was significant difference between intraspecific and interspecific aggression levels $\left(\chi^{2}=145.38, \mathrm{df}=1, p<0.001\right)$. 


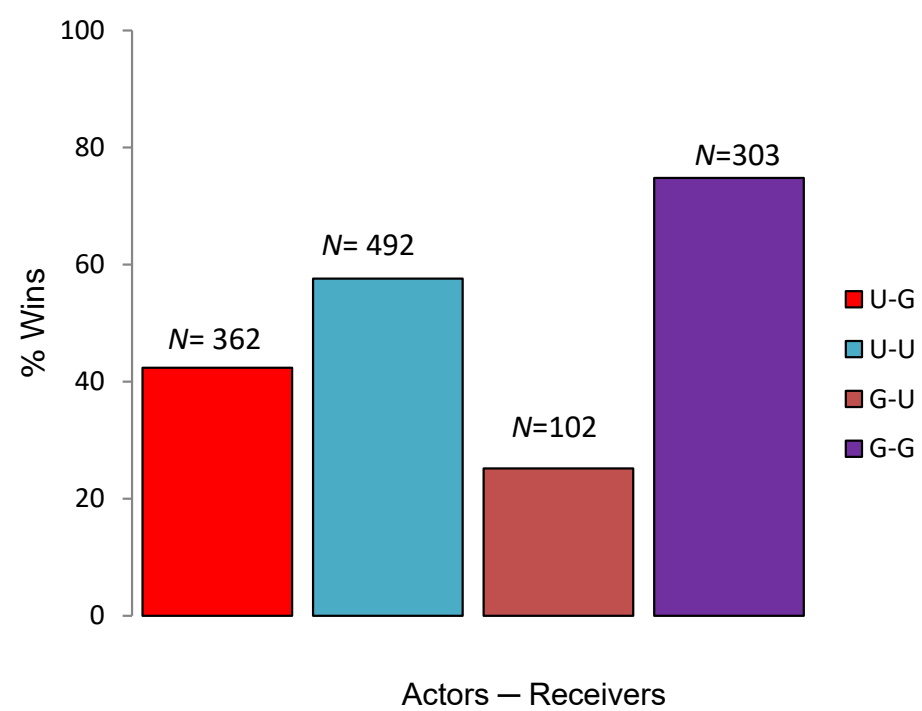

Figure 1. Percentage wins resulted from encounters between Urial-Gazelle, Urial-Urial, GazelleUrial and Gazelle-Gazelle (total count on the top of bar).

There was a significant difference among all the displayed threats behaviours, showing significant preference to rush behaviour by both species $\left(\chi^{2}=227.64, \mathrm{df}=77, p<0.001\right)$. Variety of threats displayed by Punjab urial towards Indian gazelle was diverse, including rush $51.08 \%(N=188)$, approach $41.3 \%(N=152)$, butt $5.43 \%(N=20)$, push $1.90 \%(N=7)$, and growling $0.27 \%(N=1)$ (Figure 2$)$. However, Indian gazelle displayed only rush $56.31 \%$ $(N=58)$, approach $38.43 \%(N=40)$, and butt $4.85 \%(N=5)$ (Figure 3$)$.

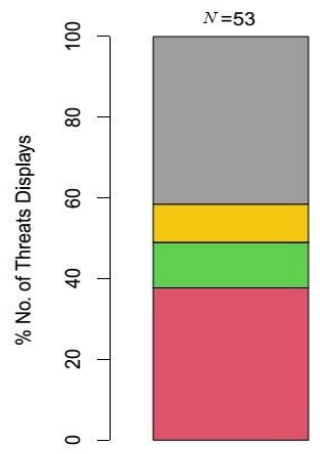

UF1

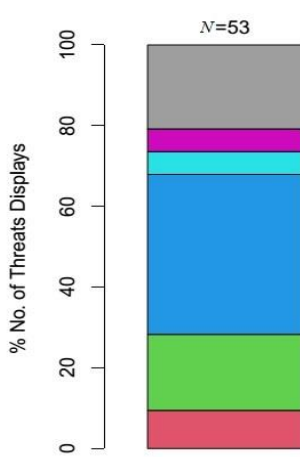

UF1

Threat Displays by Urial Towards Gazelle

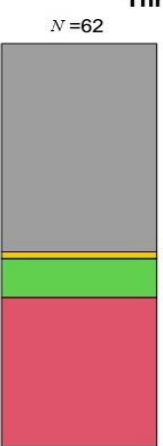

UF2

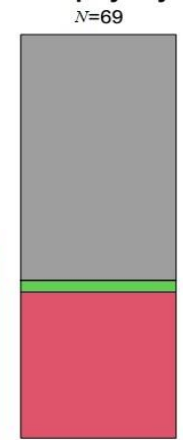

UM1

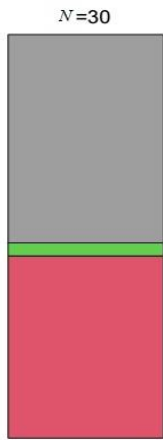

UM2

Actor

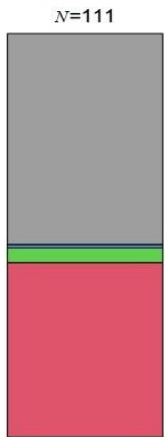

UM3

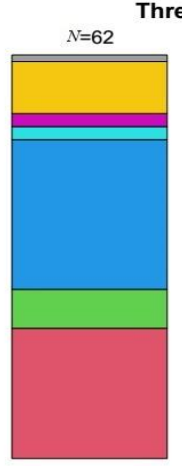

UF2

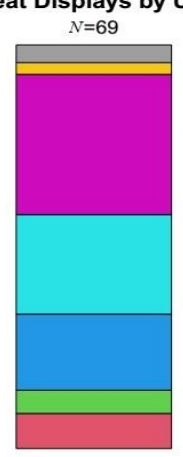

UM1

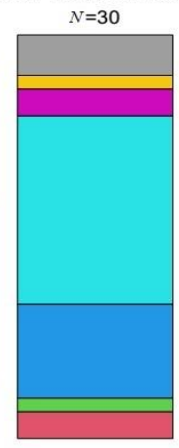

UM2
111

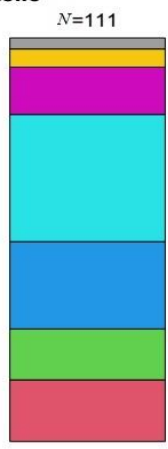

UM3

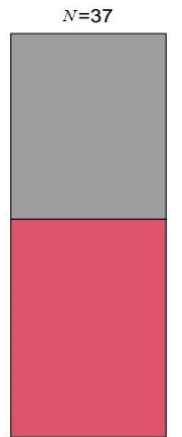

UM4

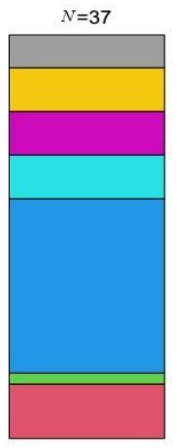

UM4
Threat

displays

口 Approach

$\square$ Butt

Growling

$\square$ Kick

Mount

$\square$ Rush

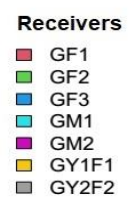

$\square$ GY1F1
$\square \quad$ GY2F2

Actor

Figure 2. Threat displays of Punjab urial towards Indian gazelle with respect to threats variety and receivers (behaviours with $0 \%$ included as a reference to overall threats). 


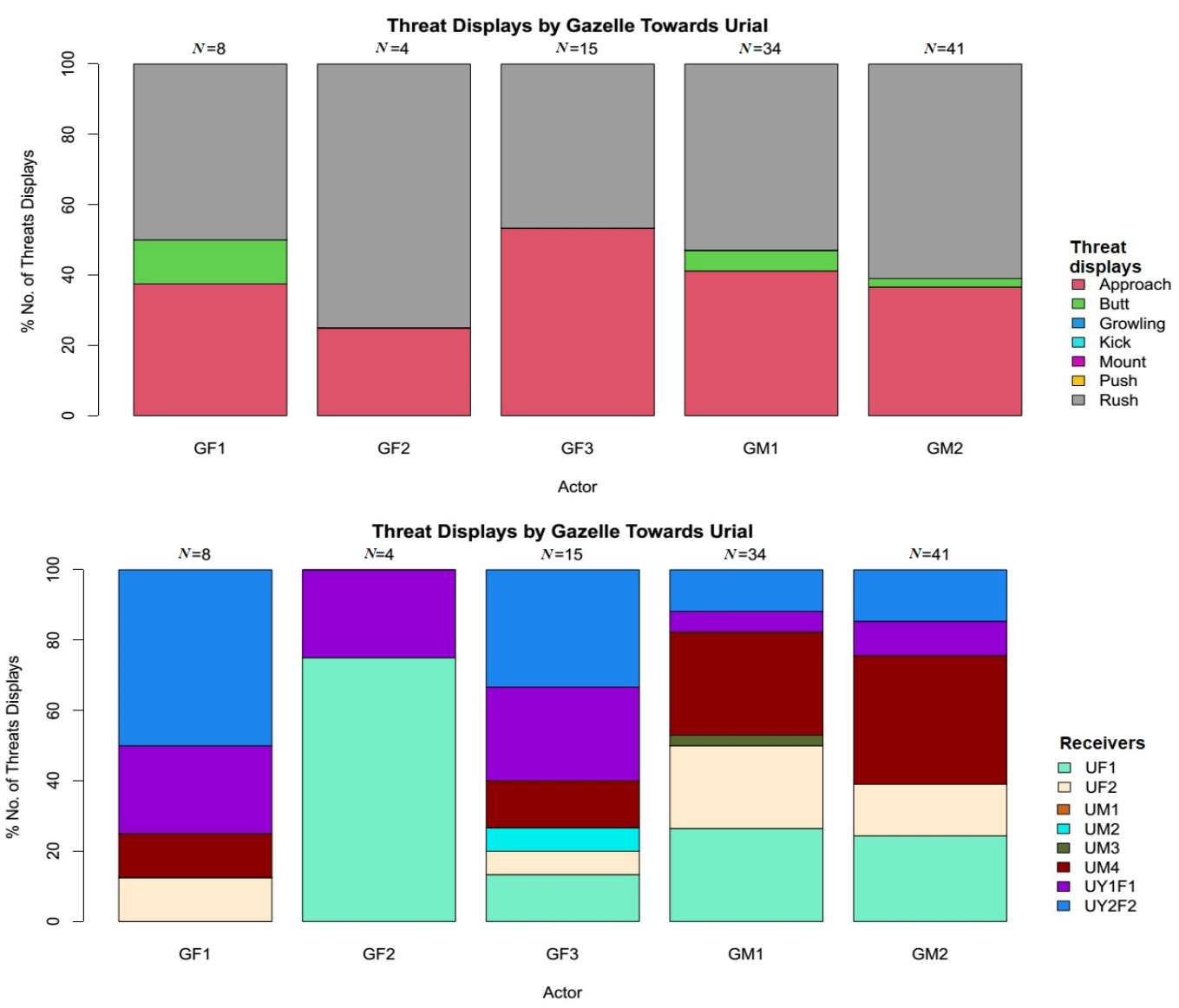

Figure 3. Threat displays of Indian gazelle towards Punjab urial with respect to threats variety and receivers (behaviours with $0 \%$ included as a reference to overall threats).

\section{Discussion}

\subsection{Overall Interactions}

The current study results reveal that both types of competitions, i.e., exploitative and interference competition, simultaneously exist between captive breeding herds of Punjab urial and Indian gazelle. Same food resources for both species seem to be the main reason for both types of competitions between the species. It has been observed that exploitative and interference competition between the competing species quickly alternates if the resources are limited [43]. In the current study, interspecific interactions seem lopsided, ranking Punjab urial as a dominant species and Indian gazelle as a subordinate species. The main reasons for such lopsided competitions are the size, strength, and weapons possessed by the dominant species [14]. This statement favours Punjab urial, rather than Indian gazelle.

Both species displayed similar threat displays, except kick and growling shown by Indian gazelle and Punjab urial, respectively. Only urial males displayed growling, which is commonly reported as a threat display in carnivores [44], and less prominent in ungulates. However, growling has been confirmed as agonistic display in Punjab urial rams [45], and other sheep species [46]. The findings in the studies mentioned above validate our results. Both Punjab urial and Indian gazelle performed the "rush" behaviour as the most powerful and determined threat displays $\left(\chi^{2}=227.64, \mathrm{df}=77, p<0.001\right)$ adding the highest percentage to their wins. Punjab urial displayed a total of 332 rush displays, contributing $25.97 \%(N=327)$ to their overall win.

On the other hand, Indian gazelle displayed "butt" with the highest frequency $(N=189)$ with a winning ratio of $8.89 \%(N=112)$. However, the win ratio attributed to "rush" $(N=174)$ was higher $(12.86 \%, N=162)$ than "butt". We assume that in both 
species that high rush behaviours were to establish dominance on the submissive individuals, which is true for gregarious wild artiodactyls [47]. Moreover "rush" subsequently increased the "butting" among subordinate individuals by restricting them to the single feed point. It has been reported that frequent and sometimes lethal butting occurs among bovids when they are clumped on limited feed at ground [47]. Punjab urial, especially rams, showed the highest number of aggressive "approaches" $(N=285)$, adding $19.38 \%(N=244)$ to their overall wins. We assume that the large body size of Punjab urial was the main factor to establish dominance over the conspecifics and Indian gazelle. Thus, frequently moving here and there to keep a hold on multiple feeding sites resulted in lopsided interference competition [14]. Out of total "approaches" made by Punjab urial, most $(N=151)$ were directed towards Indian gazelle, with 3.75 times fewer reversal approaches $(N=40)$ from Indian gazelles towards Punjab urial. These results indicate the subordinate rank [48], for Indian gazelle concerning Punjab urial. Surprisingly every "approach" by either species towards each other resulted in a win for the respective actor and a loss for the receiver.

The present study showed that many agonistic interactions during feeding resulted in displacements. However, most of these were resolved by the recipient's submissive behaviors without any overt threat response, especially by Indian gazelle. Similar findings have been reported for other wild ungulates species [49-51]. In both species, males were highly aggressive. In Punjab urial, the highest threat was displayed by UM3 $(N=389)$ followed by UM1 $(N=260)$ and UM2 $(N=141)$. UM3, being a sub-adult male in the study, was highly aggressive, probably because it was more alert and established dominance among the older males avoiding any possible threat from the younger individuals [52]. During the study period, UM1 and UM2 age were 6 years and 5 years, respectively; however, UM3 was 3.5 years old. It has been found that in wild sheep and goat, the ability to win feeding contests in males declines after 5 years of age [48]. In the case of Indian gazelle GM1 and GM2, both adult males were highly aggressive. The dominance rank in antelopes is related to age, body size, and horns. Usually, the adult males are dominant over the other conspecifics [53-56].

\subsection{Urial-Gazelle Interactions}

The current study showed that Punjab urial is highly intolerant towards Indian gazelle. Indian gazelle is a nomadic and semi-nomadic species of deserts, sand dunes, semi-deserts, and arid range lands, adapted to movements searching for ephemeral and seasonal forage [57]. However, Punjab urial is resident to its habitats with comparatively higher elevations, and forages on all kinds of vegetation ranging from grasses to shrubs and trees [58]. We assume that based on habitat and diet preferences, both these species' ecological niche is a bit different. Species with different ecological niches can easily coexist $[59,60]$, but that is true when living in their natural wild habitats.

Moreover, according to the "Optimal foraging theory" [61,62], both these species have narrowed their niches and are more concentrated on the same food source. Thus, interspecific encounters are increased manyfold [63]. Based on the results, we assume a constant overlap due to the same feed sources in captivity exists between Punjab urial and Indian gazelle. This existing overlap amplifies the potential for interspecific competition between the two species $[17,64-66]$, making Punjab urial as the more intolerant species due to its bigger size and high energy demands.

Among the horned ungulates, rush and approach towards the opponent are the powerful and preferred threat displays $[67,68]$ to conquer food or mates. The dominant individuals predominantly perform these two threat displays and anticipate the actors' wins [67]. The results obtained in the current study are in agreement with the above statements. Both species preferred "rush" and "approach" against each other (Figures 2 and 3). However, Punjab urial aggression is many folds higher, which demonstrates its dominance over Indian gazelle. Gazelles, in particular, when approaching or rushing at opponents, utter and make relatively louder and repeated snoring [67]. However, in the current study, 
no such behaviour was recorded for gazelles; instead, Punjab urial performed this threat display both towards conspecifics and Indian gazelle.

In both groups, the highly displaced individuals were females $\left(\chi^{2}=413.8, \mathrm{df}=1\right.$, $p<0.001$ ) (Figures 2 and 3). Similar results for the high displacement of females from feeding sites have been reported for other ungulates [63]. Usually, the females need to consume more and have a high energy food intake to satisfy high energy demands due to gestation and lactation [69]. In the current study, except one female (GF3), all the other urial and gazelle females were with their lambs and fawns. Therefore, we assume that females in both herds made much movement to access more food, and subsequently faced higher encounters and displacements. Among Punjab urial males, a yearling male (UM4) was the only male individual highly displaced $(N=28)$ by Indian gazelle. The UM4 was highly displaced by the dominant conspecifics, leading to higher approaches to other feeding sites; thus, subsequently becoming an easy target for the adult and more experienced gazelles.

According to the experiences and reports published by the American Zoo Association (AZA) regarding mixed species exhibits, these reveal that, in so many cases, the mixed species exhibits was not a successful practice. Particularly, in most of mixed species exhibits, Gazelle species were separated from other ungulates, either due to exerting extreme levels of aggression or receiving highly lopsided aggression from heterospecifics. Similar evidences were also reported for Mouflon sheep which is a close relative to Urial, against other ungulates (http:/ / www.azaungulates.org/mixed-species, accessed on 8 March 2020).

\section{Conclusions}

Our study indicates that Punjab urial stands out dominant over Indian gazelle owing to its physical size and strength. We assume such high suppression rates for Indian gazelle by Punjab urial can potentially affect the feeding behaviour, growth rates, and later reproduction. Although keeping mixed herds in captivity increases social enrichment and animal welfare, only the different species maintain positive or balanced offensive interactions. Based on the results obtained in the current study, we assume that, in captivity, Punjab urial is not compatible with Indian gazelle, and such high levels of aggression can possibly result in injuries or even death of the weak counterparts. As both the species are locally endangered and are raised with the aim of re-introduction; therefore, to avoid any damage or loss to the existing stocks, our findings discourage practising combined captive breeding of wild sheep and antelopes. Social enrichment, in this particular case, seems better if provided through conspecifics. Furthermore, it is strongly recommended to also provide these animals with other environmental enrichments such as physical, sensory and dietary.

Author Contributions: Conceptualization, R.H.K. and Z.L.; methodology, R.H.K.; software, T.M.; validation, Z.L., L.T. and R.H.K.; formal analysis, T.M.; investigation, R.H.K. and E.U.R.; resources, L.T.; data curation, R.H.K. and Z.Z.; writing—original draft preparation, R.H.K.; writing-review and editing, R.H.K. and E.U.R.; visualization, L.T. and Z.Z.; supervision, Z.L.; project administration, Z.L. and L.T.; funding acquisition, Z.L. and L.T. All authors have read and agreed to the published version of the manuscript.

Funding: This study was supported by the National Nature Science Foundation of China (31870512), and the fundamental research funds for the central universities (2572014CA03). This study also received financial support from Heilongjiang Touyan innovation team program for forest ecology and conservation, Ningxia Helan Mountains National Nature Reserve. The funders have no role in study design, write-up or publishing.

Institutional Review Board Statement: Not applicable.

Data Availability Statement: All the data sets obtained are presented in this article.

Acknowledgments: We pay very special thanks to Sandro Lovari for his valuable guidance throughout this study. We are grateful to the Khyber Pakhtunkhwa Wildlife Department, Pakistan, for allowing us to carry out our study. 
Conflicts of Interest: The authors declare no conflict of interest.

\section{References}

1. Wörner, L. Aggression and Competition for Space and Food in Captive Juvenile Tuatara (Sphenodon punctatus). (Dissertation); Victoria University of Wellington: Wellington, New Zealand, 2009. Available online: http://hdl.handle.net/10063/1163 (accessed on 28 January 2021).

2. Case, T.J.; Gilpin, M.E. Interference competition and niche theory. Proc. Natl. Acad. Sci. USA 1974, 71, 3073-3077. [CrossRef]

3. Amarasekare, P. Interference competition and species coexistence. Proc. R. Soc. Lond. Ser. B Biol. Sci. 2002, 269, 2541-2550. [CrossRef]

4. Ziv, Y.; Abramsky, Z.; Kotler, B.P.; Subach, A. Interference competition and temporal and habitat partitioning in two gerbil species. Oikos 1993, 66, 237-246. [CrossRef]

5. Berger, K.M.; Gese, E.M. Does interference competition with wolves limit the distribution and abundance of coyotes? J. Anim. Ecol. 2007, 76, 1075-1085. [CrossRef] [PubMed]

6. Caro, T.M.; Stoner, C.J. The potential for interspecific competition among African carnivores. Biol. Conserv. 2003, 110, 67-75. [CrossRef]

7. Razgour, O.; Korine, C.; Saltz, D. Does interspecific competition drive patterns of habitat use in desert bat communities? Oecologia 2011, 167, 493-502. [CrossRef] [PubMed]

8. Colman, J.E.; Tsegaye, D.; Pedersen, C.; Eidesen, R.; Arntsen, H.; Holand, Ø.; Mann, A.; Reimers, E.; Moe, S.R. Behavioral interference between sympatric reindeer and domesticated sheep in Norway. Rangel. Ecol. Manag. 2012, 65, 299-308. [CrossRef]

9. Broekhuis, F.; Cozzi, G.; Valeix, M.; McNutt, J.W.; Macdonald, D.W. Risk avoidance in sympatric large carnivores: Reactive or predictive? J. Anim. Ecol. 2013, 82, 1098-1105. [CrossRef]

10. Elliott, J.M. Interspecific interference and the functional response of four species of carnivorous stoneflies. Freshw. Biol. 2003, 48, 1527-1539. [CrossRef]

11. Palomares, F.; Caro, T.M. Interspecific killing among mammalian carnivores. Am. Nat. 1999, 153, 492-508. [CrossRef]

12. Berger-Tal, O.; Mukherjee, S.; Kotler, B.P.; Brown, J.S. Look before you leap: Is risk of injury a foraging cost? Behav. Ecol. Sociobiol. 2009, 63, 1821-1827. [CrossRef]

13. Abramsky, Z.; Rosenzweig, M.L.; Subach, A. The cost of interspecific competition in two gerbil species. J. Anim. Ecol. 2001, 70, 561-567. [CrossRef]

14. Peters, R.H.; Peters, R.H. The Ecological Implications of Body Size; Cambridge University Press: Cambridge, UK, 1986; Volume 2, ISBN 052128886X.

15. Ferry, N.; Dray, S.; Fritz, H.; Valeix, M. Interspecific interference competition at the resource patch scale: Do large herbivores spatially avoid elephants while accessing water? J. Anim. Ecol. 2016, 85, 1574-1585. [CrossRef] [PubMed]

16. Sinclair, A.R.E.; Norton-Griffiths, M. Does competition or facilitation regulate migrant ungulate populations in the Serengeti? A test of hypotheses. Oecologia 1982, 53, 364-369. [CrossRef]

17. Arsenault, R.; Owen-Smith, N. Facilitation versus competition in grazing herbivore assemblages. Oikos 2002, 97, 313-318. [CrossRef]

18. Putman, R.J.; Putman, R. Competition and Resource Partitioning in Temperate Ungulate Assemblies; Springer Science \& Business Media: Berlin, Germany, 1996; Volume 3, ISBN 0412612402.

19. Marshal, J.P.; Bleich, V.C.; Andrew, N.G. Evidence for interspecific competition between feral ass Equus asinus and mountain sheep Ovis canadensis in a desert environment. Wildlife Biol. 2008, 14, 228-236. [CrossRef]

20. Donadio, E.; Buskirk, S.W. Diet, morphology, and interspecific killing in Carnivora. Am. Nat. 2006, 167, 524-536. [CrossRef] [PubMed]

21. Mori, E.; Ferretti, F.; Fattorini, N. Alien war: Ectoparasite load, diet and temporal niche partitioning in a multi-species assembly of small rodents. Biol. Invasions 2019, 21, 3305-3318. [CrossRef]

22. Ferretti, F.; Mori, E. Displacement interference between wild ungulate species: Does it occur? Ethol. Ecol. Evol. 2020, 32, 2-15. [CrossRef]

23. Froese, A.D.; Burghardt, G.M. Food competition in captive juvenile snapping turtles, Chelydra serpentina. Anim. Behav. 1974, 22, 735-740. [CrossRef]

24. Boccia, M.L.; Laudenslager, M.; Reite, M. Food distribution, dominance, and aggressive behaviors in bonnet macaques. Am. J. Primatol. 1988, 16, 123-130. [CrossRef]

25. Downes, S.; Shine, R. Heat, safety or solitude? Using habitat selection experiments to identify a lizard's priorities. Anim. Behav. 1998, 55, 1387-1396. [CrossRef]

26. Grossman, G.D. Food, fights, and burrows: The adaptive significance of intraspecific aggression in the bay goby (Pisces: Gobiidae). Oecologia 1980, 45, 261-266. [CrossRef] [PubMed]

27. Packer, C. Reproductive success in lions. In Reproductive Success; University of Chicago Press: Chicago, IL, USA, 1988; pp. 363-383

28. English, P.R.; Wilkinson, V. Management of the sow and litter in late pregnancy and lactation in relation to piglet survival and growth. In Control of Pig Reproduction; Butterworth: London, UK, 1982; pp. 479-506.

29. Ferguson, G.W.; Fox, S.F. Annual variation of survival advantage of large juvenile side-blotched lizards, Uta stansburiana: Its causes and evolutionary significance. Evolution 1984, 38, 342-349. [PubMed] 
30. Khattak, R.H.; Liu, Z.; Teng, L. Development and Implementation of Baseline Welfare Assessment Protocol for Captive Breeding of Wild Ungulate-Punjab Urial (Ovis vignei punjabiensis, Lydekker 1913). Animals 2019, 9, 1102. [CrossRef]

31. Khattak, R.H.; Liu, Z.; Teng, L.; Roberts, N. Determining Optimal Stock Density of Punjab Urial (Ovis vignei punjabiensis) in Captivity for Breeding, Population Growth and Reintroduction Potential. Pak. J. Biol. Sci. 2020, 23, 1227-1230.

32. Sheikh, K.M.; Molur, S. Status and red list of Pakistan's mammals. In Proceedings of the Based on the Conservation Assessment and Management Plan Workshop, IUCN, Islamabad Pakistan, 18-22 August 2003.

33. Deutsch, J.C.; Lee, P.C. Dominance and feeding competition in captive rhesus monkeys. Int. J. Primatol. 1991, 12, 615-628. [CrossRef]

34. Gosler, A. Aspects of Bill Morphology in Relation to Ecology in the Great Tit, Parus Major. Ph.D. Thesis, University of Oxford, Oxford, UK, 1987.

35. Ekman, J.B.; Lilliendahl, K. Using priority to food access: Fattening strategies in dominance-structured willow tit (Parus montanus) flocks. Behav. Ecol. 1993, 4, 232-238. [CrossRef]

36. Witter, M.S.; Cuthill, I.C. The ecological costs of avian fat storage. Philos. Trans. R. Soc. London. Ser. B Biol. Sci. 1993, 340, 73-92.

37. Burghardt, G.M.; Layne, D.G. Effects of ontogenetic processes and rearing conditions. In Health and Welfare of Captive Reptiles; Springer: Dordrecht, The Netherlands, 1995; pp. 165-185.

38. Sakata, J.T.; Gupta, A.; Chuang, C.-P.; Crews, D. Social experience affects territorial and reproductive behaviours in male leopard geckos, Eublepharis macularius. Anim. Behav. 2002, 63, 487-493. [CrossRef]

39. Buchanan-Smith, H.M.; Griciute, J.; Daoudi, S.; Leonardi, R.; Whiten, A. Interspecific interactions and welfare implications in mixed species communities of capuchin (Sapajus apella) and squirrel monkeys (Saimiri sciureus) over 3 years. Appl. Anim. Behav. Sci. 2013, 147, 324-333. [CrossRef]

40. Buchanan-Smith, H.M. Environmental enrichment for primates in laboratories. Adv. Sci. Res. 2011, 5, 41-56. [CrossRef]

41. Veasey, J.; Hammer, G. Managing captive mammals in mixed-species communities. In Wild Mammals in Captivity: Principles and Techniques; University of Chicago Press: Chicago, IL, USA, 2010; pp. 151-161.

42. Lovari, S.; Pellizzi, B.; Boesi, R.; Fusani, L. Mating dominance amongst male Himalayan tahr: Blonds do better. Behav. Processes 2009, 81, 20-25. [CrossRef] [PubMed]

43. Rudolf, V.H.W.; McCrory, S. Resource limitation alters effects of phenological shifts on inter-specific competition. Oecologia 2018, 188, 515-523. [CrossRef] [PubMed]

44. Petak, I. Patterns of carnivores' communication and potential significance for domestic dogs. Period. Biol. 2010, 112, 127-132.

45. Schaller, G.B.; Mirza, Z.B. On the behaviour of Punjab urial (Ovis orientalis punjabiensis). In The Behaviour of Ungulates and Its Relation to Management; IUCN publications: Unwin Brothers Limited, Morges, Switzerland, 1974; pp. $306-323$.

46. Grubb, P.; Jewell, P.A. The rut and the occurrence of oestrus in the Soay sheep on St. Kilda. J. Reprod. Fertil. 1973, 491-502.

47. Geist, V.; Walther, F. Behaviour of ungulates and its relation to management. In Symposium on the Behavior of Ungulates and Its Relation to Management (1971: Calgary, Alta.); International Union for Conservation of Nature and Natural Resources: Unwin Brothers Limited, Morges, Switzerland, 1974.

48. Shi, J.; Dunbar, R.I.M. Feeding competition within a feral goat population on the Isle of Rum, NW Scotland. J. Ethol. 2006, 24, 117-124. [CrossRef]

49. Rutberg, A.T. Factors influencing dominance status in American bison cows (Bison bison). Z. Tierpsychologie 1983, 63, $206-212$. [CrossRef]

50. Bennett, B. Social dominance in female bighorn sheep. Zoo Biol. 1986, 5, 21-26. [CrossRef]

51. Veiberg, V.; Loe, L.E.; Mysterud, A.; Langvatn, R.; Stenseth, N.C. Social rank, feeding and winter weight loss in red deer: Any evidence of interference competition? Oecologia 2004, 138, 135-142. [CrossRef]

52. Pecorella, I.; Fattorini, N.; Macchi, E.; Ferretti, F. Sex/age differences in foraging, vigilance and alertness in a social herbivore. Acta Ethol. 2019, 22, 1-8. [CrossRef]

53. Barrette, C.; Vandal, D. Social rank, dominance, antler size, and access to food in snow-bound wild woodland caribou. Behaviour 1986, 97, 118-145. [CrossRef]

54. Clutton-Brock, T.H.; Green, D.; Hiraiwa-Hasegawa, M.; Albon, S.D. Passing the buck: Resource defence, lek breeding and mate choice in fallow deer. Behav. Ecol. Sociobiol. 1988, 23, 281-296. [CrossRef]

55. McElligott, A.G.; Gammell, M.P.; Harty, H.C.; Paini, D.R.; Murphy, D.T.; Walsh, J.T.; Hayden, T.J. Sexual size dimorphism in fallow deer (Dama dama): Do larger, heavier males gain greater mating success? Behav. Ecol. Sociobiol. 2001, 49, 266-272. [CrossRef]

56. Jennings, D.J.; Gammell, M.P.; Carlin, C.M.; Hayden, T.J. Is difference in body weight, antler length, age or dominance rank related to the number of fights between fallow deer (Dama dama)? Ethology 2006, 112, 258-269. [CrossRef]

57. Dookia, S.; Rawat, M.; Jakher, G.R.; Dookia, B.R. Status of the Indian Gazelle (Gazella bennettii Sykes, 1831) in the Thar Desert of Rajasthan, India. In Faunal Ecology and Conservation of the Great Indian Desert; Springer: Berlin/Heidelberg, Germany, 2009; pp. 193-207.

58. Hussain, I.; Munir, M.; Anwar, M. Food Habits of Punjab Urial, Ovis vignei punjabiensis Lydekker, 1913, in Chumbi Surla Wildlife Sanctuary, Chakwal, Pakistan. ACTA Zool. Bulg. 2015, 67, 507-514.

59. Gause, G.F. The Struggle for Existence; Williams and Wilkins Company: Philadelphia, PA, USA, $1934 ;$ p. 163.

60. Bagchi, S.; Goyal, S.P.; Sankar, K. Niche relationships of an ungulate assemblage in a dry tropical forest. J. Mammal. 2003, 84, 981-988. [CrossRef] 
61. MacArthur, R.H.; Pianka, E.R. On optimal use of a patchy environment. Am. Nat. 1966, 100, 603-609. [CrossRef]

62. Schoener, T.W. Theory of feeding strategies. Annu. Rev. Ecol. Syst. 1971, 2, 369-404. [CrossRef]

63. Ferretti, F.; Sforzi, A.; Lovari, S. Behavioural interference between ungulate species: Roe are not on velvet with fallow deer. Behav. Ecol. Sociobiol. 2011, 65, 875-887. [CrossRef]

64. Hobbs, N.T.; Baker, D.L.; Bear, G.D.; Bowden, D.C. Ungulate grazing in sagebrush grassland: Mechanisms of resource competition. Ecol. Appl. 1996, 6, 200-217. [CrossRef]

65. Gurnell, J.; Wauters, L.A.; Lurz, P.W.W.; Tosi, G. Alien species and interspecific competition: Effects of introduced eastern grey squirrels on red squirrel population dynamics. J. Anim. Ecol. 2004, 73, 26-35. [CrossRef]

66. Ahola, M.P.; Laaksonen, T.; Eeva, T.; Lehikoinen, E. Climate change can alter competitive relationships between resident and migratory birds. J. Anim. Ecol. 2007, 76, 1045-1052. [CrossRef] [PubMed]

67. Walther, F.R. Some reflections on expressive behaviour in combats and courtship of certain horned ungulates. In The Behaviour of Ungulates and its Relation to Management; IUCN: Morges, Switzerland, 1974; Volume 1, pp. 56-106.

68. Espmark, Y. Dominance relationships as a possible regulating factor in roe deer and reindeer populations. In The Behavior of Ungulates and Its Relation to Management; Geist, V., Walthers, F., Eds.; IUCN: Morges, Switzerland, 1974; pp. e787-e796.

69. Main, M.B.; Weckerly, F.W.; Bleich, V.C. Sexual segregation in ungulates: New directions for research. J. Mammal. 1996, 77, 449-461. [CrossRef] 